\title{
Good Outcomes in Kidney Transplantation With Deceased Donor With Acute Kidney Injury: Donor's Age and Not Acute Kidney Injury Predicts Graft Function
}

\author{
H. Si Nga, H.M. Takase, A.M. Bravin, P.D. Garcia, M.M. Contti, C.A. Kojima, and L.G.M. de Andrade* \\ From the Department of Internal Medicine-UNESP, Universidade Estadual Paulista, Botucatu, São Paulo, Brazil
}

\begin{abstract}
Background. With the increased demand for kidney transplants and the short supply of organs, it is necessary to have a better strategy to evaluate the available organs, especially from donors with acute kidney injury (AKI), because these organs are often rejected for transplantation.

Methods. We evaluated patients undergoing transplantation with kidneys from deceased donors with AKI. The cases were divided into AKI stages according to the Acute Kidney Injury Network (AKIN) criteria. The outcomes examined were delayed graft function (DGF), creatinine $(\mathrm{Cr})$, and creatinine clearance $(\mathrm{CrCl})$ at 6 months after transplantation.

Results. We evaluated 101 patients and included 53 in the final model. There was no statistical difference in the demographic characteristics, comorbidities, and immunosuppression according to each AKIN stage, showing a population of homogeneous transplant recipients. Recipients in AKIN stages I, II, and III, respectively had DGF in 72.7\%, 61.9\%, and $71.4 \%$ of cases; $\mathrm{Cr}$ of $1.6 \pm 0.5,1.7 \pm 0.7$, and $1.6 \pm 0.2 \mathrm{mg} / \mathrm{dL}$ at 6 months; and $\mathrm{CrCl}$ of $60.6 \pm 22.4,52.4 \pm 27.4$, and $52.03 \pm 12.1 \mathrm{~mL} / \mathrm{min}$ at 6 months. Each additional year in donor age increased the relative risk of DGF by $1.08(1.0-1.13)(P=.01)$, and organs from older donors were associated with worse renal function at 6 months.

Conclusion. Kidney transplantation of organs from deceased donors with AKI showed greater DGF but good outcomes. Donor age was the only characteristic that correlated with outcome.
\end{abstract}

$\mathbf{W}$ TH the increasing number of patients waiting for kidney transplantation, there is a greater demand for organs. There is an imbalance in offers of organs to transplant, and a need to expand the deceased donor pool [1]. Organs from donors with acute kidney injury (AKI) are usually discarded because of the possibility of adverse outcomes. Use of these organs may result in more delayed graft function (DGF) and worse renal function, because AKI is an independent risk factor for chronic kidney disease (CKD) $[2,3]$. Nevertheless, it is assumed that AKI in deceased donors is commonly caused by hypoxic-ischemic and/or nephrotoxic lesions, which are potentially reversible [4]. In addition, we do not know what terminal creatinine $(\mathrm{Cr})$ value in a deceased donor would determine the discarding of the organ [4,5]. Most studies show favorable results in donors

$0041-1345 / 16$

http://dx.doi.org/10.1016/j.transproceed.2016.06.004 with AKI [6-9]. Siedlecki et al showed favorable outcomes of creatinine clearance $(\mathrm{CrCl})$ at 6 months despite the higher rate of DGF [6], and other studies confirm these findings in regard to long-term renal function [7,8]. It has also been noted that there are good outcomes for organs of donors with AKI who had only a slight injury on biopsy [9].

The aim of this study was to describe the results of patients undergoing transplantation of kidneys from deceased donors with AKI, and the impact on renal function at 6 months after transplantation.

*Address correspondence to Luis Gustavo Modelli de Andrade, Department of Internal Medicine-UNESP, Univ Estadual Paulista, Rubião Jr, s/n-Botucatu/SP, 18.618-970 Brazil. E-mail: landrade@fmb.unesp.br

(c) 2016 Elsevier Inc. All rights reserved. 230 Park Avenue, New York, NY 10169 


\section{PATIENTS AND METHODS}

This was an observational retrospective study of all patients who underwent renal transplantation with deceased donor kidneys at the Universidade Estadual Paulista (UNESP), from January 2010 to September 2014. We selected all cases in which the donor had AKI. The AKI patients were divided into stages according to the Acute Kidney Injury Network (AKIN) criteria [10] based on initial and terminal creatinine values.

We excluded patients whose stage of AKI could not be determined because of a lack of baseline $\mathrm{Cr}$ or initial $\mathrm{Cr}$ data, and patients with $<6$ months of follow-up.

The recipient baseline characteristics examined were age, sex, race/ethnicity, underlying disease, induction therapy, immunosuppression, and panel reactive antibody. The donor baseline characteristics were age, creatinine, cause of death, and presence of hypertension or diabetes.

We evaluated as outcomes the number of days of hospitalization (length of stay), DGF, $\mathrm{Cr}$, and $\mathrm{CrCl}$ at 6 months after transplantation and compared these outcomes according to each AKI stage by AKIN criteria. The $\mathrm{CrCl}$ was estimated by the Modification of Diet in Renal Disease (MDRD) equation [11].

\section{Statistical Analysis}

Analysis of variance for parametric variables was used for the statistical analysis of continuous variables, and the Kruskal-Wallis test was used for nonparametric variables. For categorical variables, the $\chi^{2}$ test was used. Binary logistic regression was used for the multivariate analysis, considering the DGF risk, and adjusting for donor age, AKIN stage, and panel reactive antibody. Multivariate linear regression analysis was also performed with $\mathrm{CrCl}$ at 6 months as the dependent variable and adjusted to AKIN stages, donor age, cause of death, panel reactive antibody, and DGF. We constructed a classification tree model having as the dependent variable the $\mathrm{CrCl}$ at 6 months and tested as variables donor age, cause of death, panel reactive antibody, and DGF with the CHAID growing method. The significance level was set at $P<.05$. SPSS version 20 software was used.

\section{RESULTS}

We evaluated 101 patients undergoing transplantation with kidneys from deceased donors with AKI. We excluded 48 patients, 27 because we could not determine AKIN stage and 11 because they had less than 6 months of follow-up; in addition, 8 patients died before 6 months, 1 graft was lost (surgical cause) in less than 6 months, and 1 patient were transferred. A total of 53 patients were included in the final model.

The recipient characteristics showed a predominantly male population of white ethnicity, in the fifth decade of life; systemic arterial hypertension and diabetes mellitus were the main causes of CKD. Induction therapy was performed mostly with basiliximab and the standard immunosuppression consisting of tacrolimus, mycophenolate, and prednisone. Regarding the donor characteristics,

Table 1. Characteristics of Transplant Patients With Kidneys From Deceased Donors With Acute Kidney Injury

\begin{tabular}{|c|c|c|c|c|}
\hline Characteristic & AKIN I $(n=23)$ & AKIN II $(n=21)$ & AKIN III $(n=9)$ & $P$ Value \\
\hline Male sex & 17 (73.9\%) & $13(61.9 \%)$ & $6(66.7 \%)$ & NS \\
\hline White race & 17 (73.9\%) & $14(66.7 \%)$ & $7(77.8 \%)$ & NS \\
\hline Age (y) & $50 \pm 14$ & $52 \pm 13$ & $56 \pm 11$ & NS \\
\hline Underlying disease & & & & NS \\
\hline Hypertension & 8 (34.8\%) & $8(38.1 \%)$ & $3(33.3 \%)$ & \\
\hline Diabetes & 8 (34.8\%) & 5 (23.8\%) & $5(55.6 \%)$ & \\
\hline Glomerulonephritis & $4(17.4 \%)$ & 3 (14.3\%) & 0 & \\
\hline Unknown & $2(8.7 \%)$ & $3(14.3 \%)$ & $1(11.1 \%)$ & \\
\hline Other & $1(4.3 \%)$ & $2(9.5 \%)$ & 0 & \\
\hline Induction therapy & & & & NS \\
\hline Basiliximab & $20(87 \%)$ & $14(66.7 \%)$ & 7 (77.7\%) & \\
\hline Thymoglobulin & $3(13 \%)$ & 7 (33.3\%) & $2(22.2 \%)$ & \\
\hline Immunosuppression & & & & NS \\
\hline Tacrolimus & $23(100 \%)$ & $21(100 \%)$ & $9(100 \%)$ & \\
\hline Mycophenolate & $20(87 \%)$ & $18(85.7 \%)$ & $9(100 \%)$ & \\
\hline Prednisone & $23(100 \%)$ & $21(100 \%)$ & $9(100 \%)$ & \\
\hline Azathioprine & $2(8.7 \%)$ & $1(4.8 \%)$ & 0 & \\
\hline SRL/EVR & $1(4.3 \%)$ & $2(9.5 \%)$ & 0 & \\
\hline Panel reactive antibody (\%) & $7 \pm 19$ & $17 \pm 31$ & $23 \pm 34$ & NS \\
\hline Donor age $(y)$ & $40 \pm 13$ & $46 \pm 12$ & $39 \pm 12$ & NS \\
\hline Donor creatinine (mg/dL) & $1.94 \pm 0.26$ & $2.38 \pm 0.46$ & $3.18 \pm 0.54$ & .05 \\
\hline Cause of donor death & & & & NS \\
\hline Cranial trauma & $13(56.5 \%)$ & 7 (33.3\%) & $3(33.3 \%)$ & \\
\hline Cerebrovascular & $9(39.1 \%)$ & $13(61.9 \%)$ & $6(66.7 \%)$ & \\
\hline Others & $1(4.3 \%)$ & $1(4.8 \%)$ & 0 & \\
\hline Donor hypertension & $10(43.5 \%)$ & $11(52.4 \%)$ & $3(33.3 \%)$ & NS \\
\hline Donor diabetes & $1(4.3 \%)$ & $2(9.5 \%)$ & 0 & NS \\
\hline
\end{tabular}

Data based on univariate analysis.

Abbreviations: NS, not significant; SRL, sirolimus; EVR, everolimus; DGF, delayed graft function; Cr, creatinine; CrCl, creatinine clearance; AKIN, Acute Kidney Injury Network. 
Table 2. Outcomes in Transplant Patients With Kidneys From Deceased Donors With Acute Kidney Injury

\begin{tabular}{lcccc}
\hline & AKIN I & AKIN II & AKIN III & $P$ \\
\hline DGF & $16(72.7 \%)$ & $13(61.9 \%)$ & $7(71.4 \%)$ & NS \\
$\begin{array}{l}\text { Length of stay } \\
\text { (days) }\end{array}$ & $16 \pm 10$ & $18 \pm 9$ & $18 \pm 11$ & NS \\
$\begin{array}{c}\text { Cr at } 6 \text { months } \\
\text { (mg/dL) }\end{array}$ & $1.6 \pm 0.5$ & $1.7 \pm 0.7$ & $1.3 \pm 0.2$ & NS \\
$\begin{array}{l}\text { CrCl at } 6 \text { months } \\
\text { (mg/dL) }\end{array}$ & $60.6 \pm 22.4$ & $52.4 \pm 27.4$ & $62.03 \pm 12$ & NS \\
\hline
\end{tabular}

Data are number (\%), or mean \pm standard deviation; based on univariate analysis.

Abbreviations: NS, not significant; DGF, delayed graft function; $\mathrm{Cr}$, creatinine; $\mathrm{CrCl}$, creatinine clearance.

the average age was the fourth decade of life, and the cause of death was predominant cranial trauma or cerebrovascular disease (Table 1).

As for the evolution of the patients, there was no statistical difference for DGF, longer hospital stay, or $\mathrm{Cr}$ and $\mathrm{CrCl}$ at 6 months in relation to AKIN stages. The DGF rates were $72.7 \%, 61.9 \%$, and $71.4 \%$ respectively for AKIN stages I, II, and III. The $\mathrm{Cr}$ values were an average of $1.6 \pm 0.5 \mathrm{mg} / \mathrm{dL}$ for stage I, $1.7 \pm 0.7 \mathrm{mg} / \mathrm{dL}$ for stage II, and $1.3 \pm 0.2 \mathrm{mg} / \mathrm{dL}$ for stage III. The $\mathrm{CrCl}$ values at 6 months were $60.6 \pm 22.4 \mathrm{~mL} / \mathrm{min}, 52.4 \pm 62 \mathrm{~mL} / \mathrm{min}$, and $62.03 \pm 12 \mathrm{~mL} / \mathrm{min}$, respectively, for stages I, II, and III (Table 2). In multivariate linear regression analysis, among the variables related to $\mathrm{CrCl}$ at 6 months, only the age of the donor was negatively related to renal function $(\beta=-0.58$, $P=.01$ ) (Table 3). In addition, multivariate logistic regression showed that donor age was an independent risk factor for DGF, with a relative risk of 1.08 (1.008-1.137, $P=.02$ ) (Table 4).

By classification tree analysis, we noted that the age of the donor was the main determinant for $\mathrm{CrCl}$ at 6 months, with an average of $57.59 \pm 23 \mathrm{~mL} / \mathrm{min}$. When the donor's age was less than 31 years, the $\mathrm{CrCl}$ rose to $77.6 \pm 28$ $\mathrm{mL} / \mathrm{min}$. On the other hand, when the donor's age was more than 54 years, the $\mathrm{CrCl}$ dropped to $38 \pm 14 \mathrm{~mL} / \mathrm{min}$ $(P=.01)$. The cause of the donor's death determined renal function in the recipient. When the cause was cranial trauma, the $\mathrm{CrCl}$ was better $(56 \pm 10 \mathrm{~mL} / \mathrm{min})$, and when cause of death was cerebrovascular disease, the renal function was worse $(31.5 \pm 8.4 \mathrm{~mL} / \mathrm{min}, P=.001)$ (Fig 1).

Table 3. Creatinine Clearance at 6 Months in Kidney Transplant Recipients

\begin{tabular}{lcc}
\hline & $\beta$ & $P$ Value \\
\hline AKIN stage & 0.06 & .62 \\
Donor age $(\mathrm{y})$ & -0.58 & .01 \\
Cause of donor death & -0.09 & .51 \\
Panel reactive antibody & 0.07 & .62 \\
Delayed graft function & 0.18 & .18 \\
\hline
\end{tabular}

Data are based on multivariate analysis and linear regression.

Abbreviation: AKIN, Acute Kidney Injury Network.
Table 4. Multivariate Analysis and Logistic Regression of Risk for Delayed Graft Function

\begin{tabular}{lll}
\hline \multicolumn{1}{c}{ Variable } & \multicolumn{1}{c}{$\mathrm{RR}(95 \% \mathrm{Cl})$} & $P$ \\
\hline Donor age $(\mathrm{y})$ & $1.08(1.008-1.137)$ & .02 \\
AKIN I & $1.02(0.13-7.8)$ & .98 \\
AKIN II & $0.40(0.05-3.0)$ & .38 \\
Panel reactive antibody & $0.99(0.96-1.02)$ & .68 \\
\hline
\end{tabular}

Abbreviations: RR, relative risk; $\mathrm{Cl}$, confidence interval; AKIN, Acute Kidney Injury Network.

\section{DISCUSSION}

The majority of recipients with deceased donor kidneys with AKI presented with DGF. The rates are around $70 \%$ for all AKIN stages. The DGF rates are similar to those found in this service in patients with deceased donor kidneys without AKI (around 60\%) [12]. These rates are also similar to the incidence of DGF in Brazil (70\%) [13]. In a study by Hall et al [14], DGF rates were slightly lower for the AKIN stages 1,2 , and 3 , which were $34 \%, 52 \%$, and $57 \%$, respectively. Similar results were found in a study by Jung et al [15], with DGF higher in patients with AKI compared to the group without AKI. Nevertheless, in the present study, the renal function of transplant recipients was good after 6 months posttransplantation at the 3 AKIN stages, with an average creatinine clearance of $60 \mathrm{~mL} / \mathrm{min}$. Then, despite the high rates of DGF in patients who received kidneys with AKI, reflecting an increased hospital stay, our patients had favorable outcomes. Hall et al [9] found the glomerular filtration rate (GFR) at 6 months to be 55 $\mathrm{mL} / \mathrm{min}$ for renal transplant patients with AKI. In native kidneys, the severity of AKI is associated with worse clinical outcomes [16,17]. In transplanted kidney, DGF is traditionally a response to AKI and it is a known risk factor to poor outcome and graft survival [14]. Based on this evidence, it seems reasonable to assume that AKI in the donor can lead to a nonfunctioning graft; however, recent clinical studies [7-9] and the present study failed to demonstrate this association.

Our results indicate that, more important than the severity of AKI, was the age of the donor. Each 1-year increase in age of the donor resulted in an $8 \%$ increased risk of DGF and also poorer renal function after 6 months. Classification tree analysis showed a division in 3 age stages (31 years, 31-54 years, and more than 54 years) that predicts renal function at 6 months. For donors older than 54 years, the main determinant of renal function was the cause of death, with better renal function if the donor's cause of death was cranial trauma.

In conclusion, in this study, transplant patients with kidneys with AKI had favorable outcomes at 6 months despite high rates of DGF. The severity of AKI appears to have no impact on renal function; instead, the age of the donor is the main risk factor for DGF and poor renal function after 6 months. The cause of death of the donor is an important determinant of renal function in donors older than 54 years. 
Cr Clearance at 6 months

\begin{tabular}{|ll|}
\hline \multicolumn{2}{|c|}{ Node 0} \\
Mean & 57,598 \\
Std. Dev. & 23,342 \\
$\mathrm{n}$ & 53 \\
$\%$ & 100,0 \\
Predicted & 57,598 \\
\hline
\end{tabular}

Donor Age (years)

Adj. P-value $=0,016, F=9,029$,

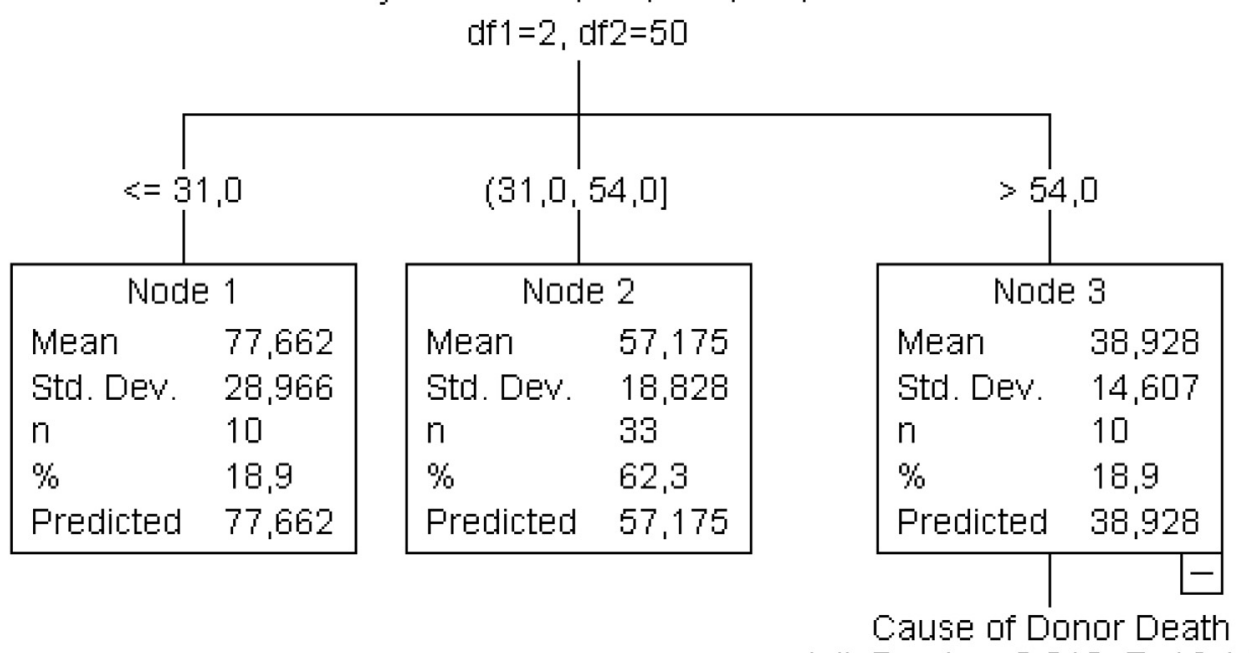

Adj. P-value $=0,012, F=16,147$,

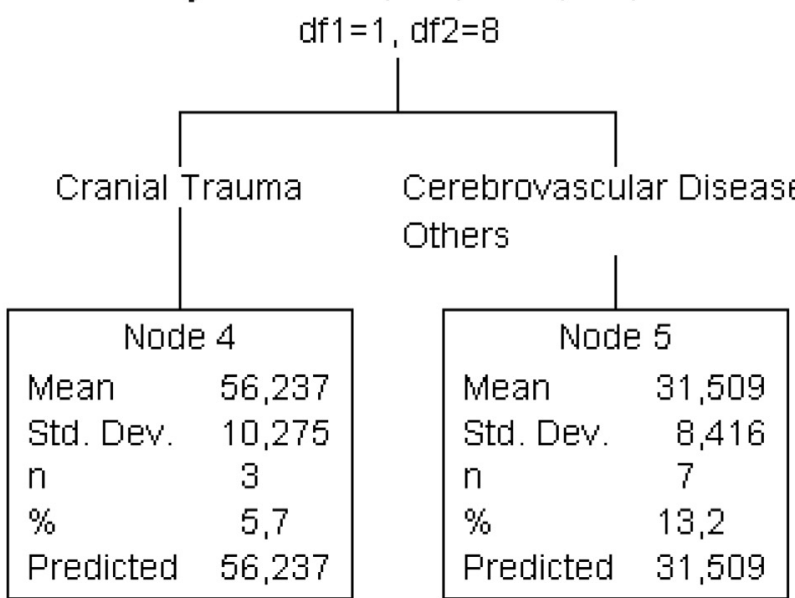

Fig 1. Classification tree model for transplant patients with deceased donor kidney with acute kidney injury (AKI). The model has as dependent variable the creatinine clearance $(\mathrm{CrCl})$ at 6 months and tests for age of donor, cause of donor death, panel reactive antibody, and delayed graft function using CHAID growing method. Std. Dev., standard deviation. 


\section{REFERENCES}

[1] Mathur AK, Ashby VB, Sands RL, Wolfe RA. Geographic variation in end-stage renal disease incidence and access to deceased donor kidney transplantation. Am J Transplant 2010;10:1069-80.

[2] Morgan C, Martin A, Shaprin R, Randhawa PS, Kayler LK. Outcomes after transplantation of deceased donors kidneys with rising serum creatinine. Am J Transplant 2007;7:1288-92.

[3] Coca SG, Singanamala S, Parikh CR. Chronic kidney disease after acute kidney injury: a systematic review and meta-analysis. Kidney Int 2012;81:442-8.

[4] Kumar A, Khan MS, Jagian SM, et al. Successful transplantation of kidneys from deceased donors with acute renal failure: three year results. Transplantation 2006;82:1640-5.

[5] Basile DP, Donohoe D, Roethe K, Osborn JL. Renal ischemic injury results in permanent damage to peritubular capillaries and influences long term function. Am J Physiol Renal Physiol 2001;281:F887-9.

[6] Siedlecki A, Irish W, Brennan DC. Delayed graft function in the kidney transplant. Am J Transplant 2011;11:2279-96.

[7] Klein R, Galante NZ, Santes-Freitas TV, Franco MF, Tedesco-Silva H, Medina-Pestana JO. Transplantation with kidneys retrieved from deceased donors with acute renal failure. Transplantation 2013;95:611-6.

[8] Kayler LK, Garzon P, Magliocca J, et al. Outcomes and utilization of kidneys from deceased donors with acute kidney injury. Am J Transplant 2009;9:367-73.

[9] Hall IE, Reese PP, Weng FL, et al. Preimplant histologic acute tubular necrosis and allograft outcomes. Clin J Am Soc Nephrol 2014;9:573-82.
[10] Mehta RL, Kellum JA, Shah SV, Molitoris BA, Ronco C, Warnock DG, et al. Acute Kidney Injury Network: report of an initiative to improve outcomes in acute kidney injury. Crit Care (Lond Engl) 2007;11:R31.

[11] Earley A, Miskulin D, Lamb EJ, Levey AS, Uhlig K. Estimating equations for glomerular filtration rate in the era of creatinine standardization: a systematic review. Ann Intern Med 2012;156:785-95.

[12] de Andrade LG, Garcia PD, Contti MM, da Silva AL, Banin VB, Duarte Jda C, et al. The 600 kidney transplants performed at the Botucatu Medical School Hospital-UNESP: changes over. J Bras Nefrol 2014;36:194-200.

[13] Helfer MS, Vican AR, Spuldaro F, Gonçalves LFS, Manfro RC. Incidence, risk factors, and outcomes of delayed graft function in deceased donor kidney transplantation in a Brazilian center. Transplant Proc 2014;46:1727-9.

[14] Hall IE, Schroppel B, Doshi MD, Ficek J, Weng FL, Hasz RD, et al. Associations of deceased donor kidney injury with kidney discard and function after transplantation. Am J Transplant 2015;15:1-9.

[15] Jung CW, Park KT, Kim SY, Kim SJ, Kim MG, Jo SK, et al. Clinical outcomes in kidney transplantation patients from deceased donors with acute kidney injury. Transplant Proc 2013;45:2941-5.

[16] Bonventre JV, Yang L. Cellular pathophysiology of ischemic acute kidney injury. J Clin Invest 2011;121:4210-21.

[17] Wald R, Quinn R, Luo J, et al. Chronic dialysis death among survivors of acute kidney injuring dialysis. JAMA 2009;302: 1179-85. 